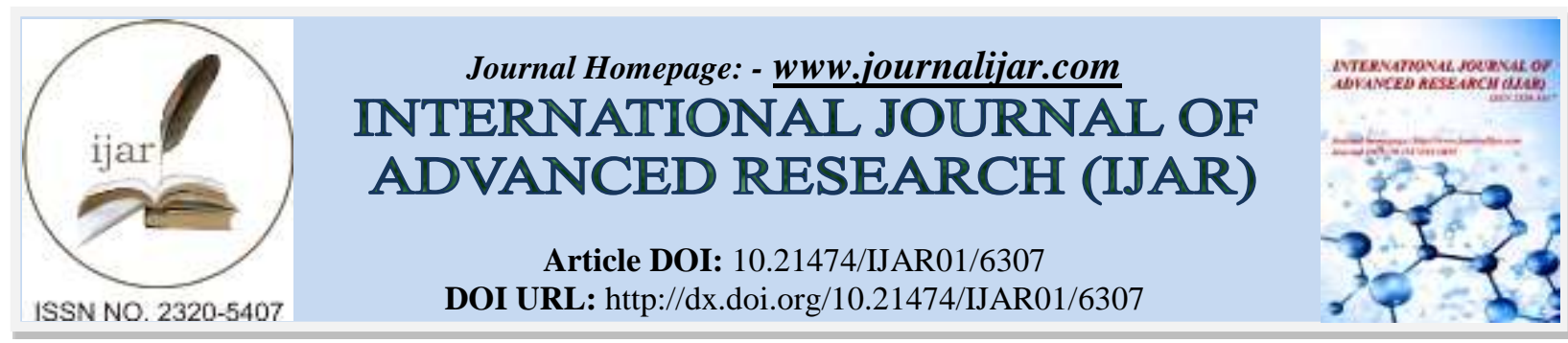

RESEARCH ARTICLE

\title{
DESIGNING AND DEVELOPING MICROPIPETTE USING THE OPEN SOURCE WARE AND 3D PRINTER.
}

\section{Douglas Mosoti Rayori ${ }^{1}$, Nyabaro Obed Mainya ${ }^{2}$ and Edwin Makworo ${ }^{3}$.}

1. Kisii University, School of Pure and Applied Sciences, Department of Biologica, P.O Box 408-40200, Kisii, Kenya.

2. Kisii University, School of Pure and Applied Sciences Chemistry department, P.O Box 408-40200, Kisii, Kenya.

3. Kisii University, School of Pure and Applied Sciences Sciences, engineering department, P.O Box 408-40200, Kisii, Kenya.

\section{Manuscript Info}

\section{Manuscript History}

Received: 14 November 2017

Final Accepted: 16 December 2017

Published: January 2018

Key words:- micropipette, precision, accuracy, open source problem.
Abstract

Micropipettes are used to measure and deliver accurate volumes of liquid. The introduction of affordable, consumer-oriented 3-D printers is a milestone in the current "maker movement," which has been heralded as the next industrial revolution. Combined with free and open sharing of detailed design blueprints and accessible development tools, rapid prototypes of complex products can now be assembled in one's own garage - a game-changer reminiscent of the early days of personal computing. At the same time, 3-D printing has also allowed the scientific and engineering community to build the "little things" that help a lab get up and running much faster and easier than ever before.

Copy Right, IJAR, 2018,. All rights reserved.

\section{Introduction:-}

Micropipette is a laboratory tool used commonly in the lab for measuring and transferring small volumes of liquids i.e. in microliters $(\mu \mathrm{L})$ with high precision and accuracy. Some of the micropipettes are of fixed volumes while others are adjustable.

Even though they are required in the laboratories, they are relatively expensive. In this project, we developed a micropipette using the open source ware and 3D printer $[1,2,3]$. The intent of this is that they can be used as teaching aids, in addition to equipping laboratories.

\section{Materials and Equipment:-}

Prusa i3 3D printer, Filament, Biro pen filling $(100 \mathrm{~mm}$ and $80 \mathrm{~mm}), 2$ Springs $(7 \mathrm{~mm} 20 \mathrm{~mm}, 5 \mathrm{~mm} 35 \mathrm{~mm})$, Screw (M3 10mm), Super glue, Rubber glove, Cellotape, and Tubing metallic with hollow tube (30 $\mathrm{mm}$ long and $5 \mathrm{~mm}$ diameter)

\section{Procedure:-}

1. Using 3D printer, print the various components of the micropipette: A, B, C, D, E, F, and G (Figure 1). The files for the various parts can be accessed from http://www.thingiverse.com/thing:64977 [3].

Figure 1: Various components of a micropipette. Parts A to $\mathrm{G}$ are printed using Prusa i3 3D printer. 
2. Fit the metallic tubing to part B snug, glue it to be air tight. The length should be appropriate for mounting of the pipette tips.

3. To the $80 \mathrm{~mm}$ biro filling tube (L), fit the $7 \mathrm{~mm}$ diameter by $20 \mathrm{~mm}$ spring $(\mathrm{K})$ and slip them into part $\mathrm{A}$, then add a screw (F)to part A.

4. To the protruding part of the biro slip part $\mathrm{L}$, cover it with part $\mathrm{F}$. 5. Combine part $\mathrm{E}$ and $\mathrm{G}$, slip the combined parts over the biro fitted into part $\mathrm{A}$ as shown below. Then adjust the screw andcombined parts as shown and then glue the combined parts E and G.

6. Obtain a glove (J), stretch it over the top part and let the glove stretch and slide over the bottom part as shown. Then tape the combined parts. Below is an example of illustration.

7. Load the $100 \mathrm{~mm}$ biro filling with $5 \mathrm{~mm} 35 \mathrm{~mm}$ spring as before, and then slide them into part A as shown. If need arises glue

8. Fit an appropriate pipette tip and try to pipette any volume of your choice, to check whether the micropipette is working properly. You can then calibrate it for measuring specific volumes.

Figure 2: Assembled micropipette.

\section{Results and Discussion:-}

Figure 2 shows a micropipette after the various components have been assembled. Then one is able to calibrate the micropipette to measure definite volumes. In general, through 3D printing technology and by using open source ware, one is able to make a micropipette relatively cheaply as some parts are locally available and accessible. Therefore, through this technology, one can equip laboratories with equipment at a relatively affordable cost [2].

\section{References:-}

1. Tom Baden (2014). Biropette: 3D printed, customizable high precision pipette. Centre for Integrative Neuroscience, University of Tü-bingen, Germany.

2. Baden T, Chagas AM, Gage G, Marzullo T, Prieto-Godino LL, Euler T (2015) Open Labware: 3-D Printing $\begin{array}{llllll}\text { Your Own Lab Equipment. PloS } & \text { Biol } & \text { 13(3): }\end{array}$ doi:10.1371/journal.pbio.1002086http://www.thingiverse.com/thing:64977 